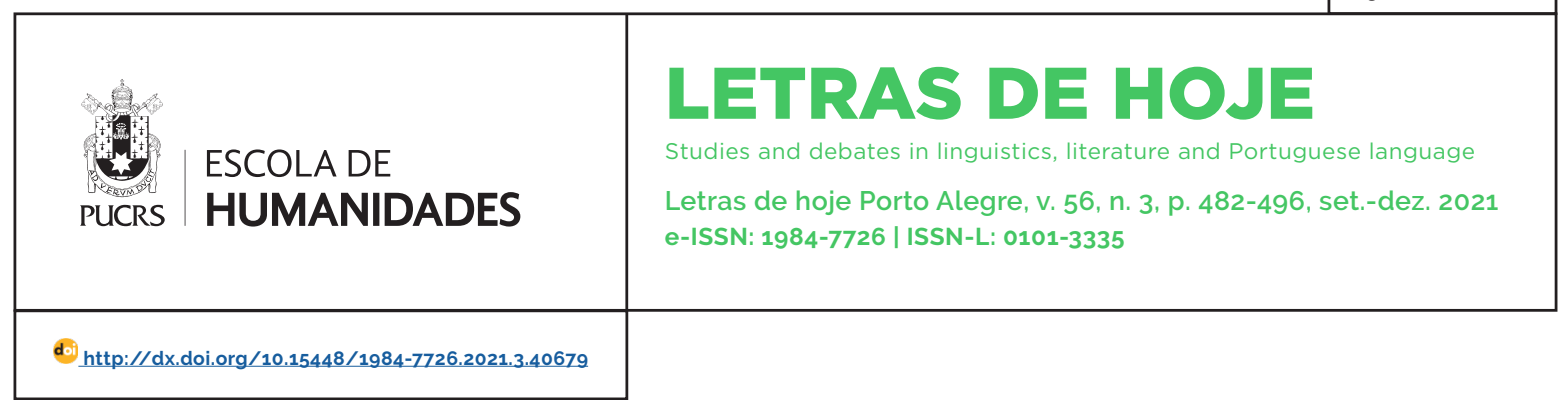

SEÇÃO: ESTUDOS BAKHTINIANOS CONTEMPORÂNEOS

\title{
O estudo dialógico da valoração
}

The dialogical study of valuation

El estudio dialógico de la valoración

Rodrigo Acosta Pereira ${ }^{1}$

orcid.org/0000-0003-0148-8725 drigo_acosta@yahoo.com.br

\section{Fernando Arthur \\ Gregol $^{1}$}

orcid.org/0000-0002-5153-338X

fgregol70@gmail.com

Recebido em: 13 abr. 2021. Aprovado em: 2 ago. 2021. Publicado em: 10 fev. 2022.
Resumo: Neste trabalho, temos por objetivo apresentar uma discussão teóricometodológica em torno do conceito de "valoração" e suas interfaces com outros conceitos da arquitetônica dos escritos de Mikhail Bakhtin e o Círculo. Para tanto, pautamos nossas discussões nas reflexões de Mikhail Bakhtin. Pável Medviédev e Valentin Volochinov e, ainda, em autores contemporâneos inseridos no campo de estudos da Análise Dialógica do Discurso (ADD). Trata-se, portanto, de uma pesquisa de revisão bibliográfica, pois buscamos delinear e revisitar caminhos de como o conceito de valoração é desenhado nos escritos do Círculo e em estudos contemporâneos da ADD. Os resultados apontam que a valoração, assim como o é com basicamente todos os conceitos da obra de M. Bakhtin e o Círculo, se engendra dialogicamente a outros conceitos cunhados pelo Círculo, tais como ideologia, cronotopo e esfera da atividade humana.

Palavras-chave: Valoração. Ideologia. Campos da atividade humana. Cronotopo.

Abstract: In this paper we aim to present a theoretical-methodological discussion around the concept of "valuation" and its interface with other concepts of Mikhail Bakhtin and his Circle's architectonic. To do so, we guide our discussion by taking the thoughts of Mikhail Bakhtin, Pável Medviédev and Valentin Volochínov. Also, we glanced to contemporary authors who are inserted in Dialogical Discourse Analysis (DDA). Therefore, this is a bibliographical research, because we chose to design paths about how the valuation concept is constructed in the Circle's thoughts and in the contemporary authors of DDA. The results show us that the valuation, basically like any other concept of M. Bakhtin and his Circle, engenders dialogically to other concepts designed by the authors from the Circle, like ideology, chronotope and social sphere of human's activity.

Keywords: Valuation. Ideology. Social spheres of human's activity. Chronotope.

Resumen: En este trabajo, nuestro objetivo es presentar una discusión teórico- metodológica en torno al concepto de "valoración" y sus interfaces con otros conceptos arquitectónicos de los escritos de Mikhail Bakhtin y el Círculo. Para eso, pautamos nuestras discusiones en las reflexiones de Mikhail Bakhtin, Pável Medviédev y Valentin Volochínov y, aún, en autores contemporáneos insertados en el campo de los estudios de la Análisis del discurso dialógico (ADD). Se trata, por lo tanto, de una investigación de revisión bibliográfica, pues buscamos delinear y revisitar caminos de como el concepto de valoración es dibujado en los escritos del Círculo y en los estudios ADD contemporáneos. Los resultados muestran que la valoración, así como ocurre con básicamente todos los conceptos del trabajo de M. Bakhtin y el Círculo, si engendra dialógicamente a otros conceptos acuñados por el círculo, tales como ideología, cronotopo, y esfera de actividad humana.

Palabras clave: Valoración. Ideología. Campos de actividad humana. Cronotopo.

\section{(c) (1)}




\section{Introdução}

O objetivo deste artigo de base bibliográfica é discutir algumas questões teórico-metodológicas a respeito do conceito de valoração ao longo dos escritos do Círculo, em especial retomando pressupostos que estão nos escritos de Valentin Volochínov, Pável Medviédev e Mikhail Bakhtin, além de reflexões contemporâneas nos estudos em Análise Dialógica do Discurso (ADD) no Brasil.

Cabe ressaltar que seria impossivel, dada a complexidade dos escritos do Círculo, de retomar o seu conjunto de reflexões em um único texto. Dessa forma, buscamos propor caminhos, possibilidades, além da retomada dos pressupostos fundacionais da teoria. Em outras palavras, a proposta caracteriza-se como uma indicação de possibilidades de leitura, indicação de caminhos possiveis de retomada dos aspectos teórico-metodológicos no conjunto das obras do Círculo para que possamos empreender estudos envoltos à análise da valoração/da avaliação social no discurso.

Para tanto, então, retomamos os escritos do Círculo, em especial os estudos dos autores já mencionados e, como reação-resposta a esses escritos, reenunciamos os interlocutores contemporâneos, cujos estudos matizam o campo que, no Brasil, denominamos de Análise Dialógica do Discurso (ADD). Com base nesse conjunto de referenciais, a proposta é delinear as principais considerações acerca dos caminhos teórico-metodológicos para análise da valoração/avaliação social de base enunciativo-discursiva dialógica.

Iniciamos apresentando os caminhos que objetivamos a percorrer ao longo da discussão presente. Em um primeiro momento, a ideia inicial é uma retomada das vozes de V. Volochínov, P. Medviédev e M. Bakhtin e esse revisitar assume-se como um caminho, uma possibilidade, uma sugestão de leitura (do conjunto da obra do Círculo) em relação a apreender o conceito de valoração/avaliação social na perspectiva dialógica. Em um segundo momento, apresentamos estudos prévios realizado por Rodrigues e Acosta Pereira (2014), por
Acosta Pereira e Brait (2020a, 2020b), por Acosta Pereira e Rohling (2020) e, por fim, um estudo de Acosta Pereira, Rodrigues e Costa-Hübes (2019), pesquisas contemporâneas em ADD, que tratam da questão da análise dialógica da valoração/ avaliação social em dados discursivos.

Então, retomando a proposta dos caminhos dessa discussão, iniciamos com as vozes do Círculo e, em um segundo momento, partimos para propostas de estudos contemporâneos em ADD.

\section{Em torno da voz de V. Volochínov, P. Medviédev e M. Bakhtin}

Inicialmente, auscultamos as vozes do Círculo, especificamente a de V. Volochínov. ${ }^{2}$ Ressaltamos que a proposta é, ao mesmo tempo, apresentar como os conceitos são delineados e cunhados pelo Círculo ao longo do conjunto das suas obras, e, em adição, retomar explicações que o Círculo postula para que possamos delinear um quadro teórico-metodológico. Iniciamos nossa discussão, portanto, partindo da concepção de Volochínov nos textos "O discurso na vida e o discurso na arte" e "A construção da enunciação" e na obra Marxismo e Filosofia da Linguagem. Em seguida, retomamos as discussões de Medviédev no livro O método formal nos estudos literários, para que, por fim, cheguemos às vozes de Bakhtin nos textos: Para uma filosofia do ato responsável, Teoria do Romance l: A estilística e Os gêneros do discurso.

Volochínov, no texto de 1926, "O discurso na vida e o discurso na arte", já estabelece questões relacionadas à valoração, como conceito de comunidades de valorações, e, também, a questão do tom principal da valoração social. Em outro escrito, o autor, em Marxismo e Filosofia da Linguagem, explica a questão do índice de valor e do índice social de valor. E, ainda, no ensaio de 1930 , "A construção da enunciação", traz a questão das valorações. Nos três ensaios mencionados, Volochinov (1926, 1929/1930, 1930) trata da questão da entonação, materialidade concreta da valoração.

Sob essa perspectiva, o que $V$. Volochínov nos explica em relação à valoração? Retoma-

2 Neste trabalho, ao longo da retomada dos escritos, não seguiremos a cronologia de publicação das obras do Círculo. 
mos cinco excertos do ensaio "A construção da enunciação", de Volochínov (2013):3

(i) todo enunciado, além da orientação social, encerra em si um sentido, um conteúdo [...]

(ii) todo enunciado efetivo e real é dotado de um sentido. Contudo, se tomarmos um enunciado qualquer, o mais comum (modelar), nem sempre podemos de imediato empreender o seu sentido. Em condições, e em um ambiente diferentes, esse enunciado sempre terá sentidos distintos [...]

(iii) A diferença nas situações determina também as diferenças dos sentidos de uma mesma expressão verbal. Nesse caso, a expressão verbal - o enunciado - reflete a situação não apenas de modo passivo. Não; ela é uma solução; torna-se uma conclusão avaliativa e ao mesmo tempo uma condição necessária de seu desenvolvimento ideológico posterior [...] (iv) A relação do enunciado com sua situação e seu auditório é criada, primeiramente, pela entonação. A situação e o auditório correspondentes determinam justamente a entonação e, por meio dela, realizam tanto a escolha das palavras quanto a sua ordenação, ou seja, já por meio dela concebem o todo do enunciado [...]

(v) A entonação é o condutor mais flexivel e sensivel daquelas relações sociais existentes os falantes em uma dada situação. Diremos que a entonação é a expressão sonora (VOLOCHINOV, 2013, p. 282, 282-283, 285, 287).

Atestamos, nesses excertos de Volochínov (2013), que a valoração se vincula à orientação social. ${ }^{4}$ Dessa forma, a orientação social do enunciado sempre é atravessada, saturada, de um valor, de um indice social de valor. Além disso, o enunciado é sempre dotado, atravessado por matizes valorativos, ou seja, cada situação de interação implica um indice social de valor, e esse indice social de valor, que atravessa a situação de interação reverbera no enunciado, e não só no enunciado enquanto construto social, mas como uma unidade de comunicação verbal e, sobretudo, na estrutura do enunciado em termos de elementos lexicais, gramaticais, que são agenciados e mobilizados nesse (em sua materialidade linguistica). Deste modo, portanto, a valoração implica nas escolhas das palavras, na dimensão dessa escolha, na sua seleção e na sua disposição no enunciado. Também a entona- ção, como um construto material, um construto concreto, realiza a valoração, e essa realização, claro, é respondente (responsiva) às demandas da situação de interação verbal.

Com isso, Volochinov (2013) explica que, inicialmente, no método sociológico, propõe-se a analisar a linguagem sob o viés do enunciado, e, portanto, o enunciado como um elo material e mediador dessa situação. A valoração vem como um construto de sentido, isto é, como a projeção axiológica, uma projeção, portanto, avaliativa que vai demandando recortes de sentido do enunciado no interior de dada situação de interação, de tal modo que esse recorte é sempre respondente às demandas da situação de interação.

Por seguinte, ao tomarmos as constatações de Medviédev (2012), no texto O Método Formal nos Estudos Literários: por uma poética sociológica, o autor também traz discussões pontuais sobre valoração. Ele se vale de outros conceitos que flutuam e orbitam ao longo da sua discussão, em especial, de avaliação social, de atmosfera axiológica, de orientação avaliativa em meio ideológico, de entoação expressiva, de gesto valorativo, de sistema de avaliações sociais, de horizonte de valores e de nuances de valores. Medviédev (2012) utiliza-se de conceitos plurais para então discutir o que seria o "valor/a avaliação social", que atravessa o enunciado. Para tanto, o autor explica que

(i) a avaliação social determina todos os aspectos do enunciado, penetrando por inteiro, porém ela encontra sua expressão mais pura e típica na entonação expressiva [...]

(ii) No enunciado, cada elemento da língua tomado como material obedece às exigências da avaliação social [...]

(iii) As possibilidades de uma língua tornam-se realidade somente por meio da avaliação [...] (iv) na verdade, a língua é criada, formulada e se desenvolve ininterruptamente nos limites de determinado horizonte de valores [...]

$E(v)$ do ponto de vista sociológico, as próprias possibilidades da lingua estão inseridas em seu surgimento e desenvolvimento, no círculo de avaliações que necessariamente se constituem um dado grupo social (MEDVIÉDEV, 2012, p. 185, 187).

\footnotetext{
Embora não haja nenhuma menção explícita do conceito/termo "valoração", entendemos que Volóchinov traz uma discussão que engendra o conceito de valoração e, portanto, a explica a partir de uma cosmovisão que circunda os conceitos cunhados pelo Círculo 4 A "orientação social", de forma geral, no conjunto das obras do Círculo, se refere ao conjunto de reflexos e refrações ideológicas e axiológicas que se movem discursivamente (de forma centrípeta e centrífuga) na vida social.
} 
Medviédev (2012), portanto, traz questões que estão próximas às levantadas por Volochínov (2013), 5 e, partir disso, apresentamos um recorte dessa discussão para mostrar como Medviédev pontua o aspecto dos elementos da língua, a questão de uma análise linguística de base sociológica para a análise do enunciado. Pontuando que a avaliação social já determina os aspectos do enunciado, enquanto material concreto de uso da língua, e, portanto, os elementos, recursos, escolhas lexicais, gramaticais, textuais, respondem a esse horizonte de valores. Eles também respondem a dada demanda de uma avaliação social que é inclusa, constitutiva, legitimada, regularizada em uma dada situação de interação. Dessa forma, segundo Medviédev (2012), desse ponto de vista sociológico que implica questões de tempo e de espaço de dada interação social, as próprias possibilidades da língua que se mobilizam e que são agenciadas por um sujeito ao enunciar, respondem, no sentido dialógico do termo, às avaliações que necessariamente constituem um dado grupo social.

Portanto, questões de avaliação social, questões de gesto valorativo, de nuances de valores, se interpenetram e se interseccionam pela escolha dos elementos da língua no interior da enunciação. Com isso, cada elemento da língua, no enunciado tomado como material de análise mobiliza recursos, que são visiveis na construção desse mesmo enunciado em termos linguísticos, e respondem às possibilidades/potencialidades da avaliação.

M. Bakhtin, por sua vez, também nos apresenta reflexões sobre valoração ${ }^{6}$. Os termos utilizados por Bakhtin em seus escritos são tom emotivo-volitivo, na obra Para uma filosofia do ato responsável (2017), tom, acentuação, reacentuação, relação valorativa e elemento expressivo como a relação subjetiva valorativa do falante com o conteúdo e o sentido do enunciado no ensaio Os gêneros do discurso (2016); e entoação expressiva e, ainda, ponto de vista e acento em Teoria do romance l: a estilistica (2017). Retomamos explicações do ensaio Os gêneros do discurso (2016) para que possamos revisitar algumas considerações de ordem teórico-metodológica. Bakhtin, então, pontua que

(i) a relação valorativa do falante com o objeto do seu discurso (seja qual for esse objeto) também determina a escolha dos recursos lexicais, gramaticais e composicionais do enunciado [...] (ii) o estilo individual do enunciado é determinado por seu aspecto expressivo [...]

(iii) [Assim], a entonação expressiva é um traço constitutivo do enunciado, pertence aqui ao enunciado e não à palavra no sentido sistêmico do termo [...]

(iv) Só o contato do significado linguístico com a realidade concreta; só o contato da língua com a realidade, contato que se dá no enunciado, gera a centelha da expressão: esta não existe nem no sistema da língua, nem na realidade objetiva existente fora de nós (BAKHTIN, 2016, p. 47, 48, 51)

M. Bakhtin traz explicações próximas, convergentes com as explicações de $\vee$. Volochínov e P. Medviédev, em especial em relação aos elementos lexicais, gramaticais e composicionais do enunciado que respondem às reverberações da relação valorativa, como também a questão da entonação expressiva como traço constitutivo material concreto e exequivel do enunciado.

Portanto, tanto Volochínov (2013) e Medviédev (2012) quanto Bakhtin (2016) reiteram a posição de que os elementos linguísticos que compõem a estrutura do enunciado são, portanto, mobilizados tanto em questões de conteúdo, estilo e composição à luz das relações da entonação e da expressão valorativa que respondem quanto às demandas impostas, regularizadas, legitimadas, pela interação social. Ambos os autores reiteram que o enunciado, na sua materialidade linguística, é um enunciado que responde à valoração social.

A partir dessas retomadas dos escritos do Círculo, o que podemos entender em termos de aproximações e convergências entre Volochínov, Medviédev e Bakhtin? Os autores entendem que, inicialmente, a valoração se engendra no

\footnotetext{
5 Um estudo outro, obviamente, é necessário para discutir de forma mais extensa e comparativa a relação entre os autores do Círculo e dos conceitos que cunharam.

6 Entendemos que, em uma ordem cronológica, Bakhtin foi o primeiro a discutir o termo, porém sua obra é mais extensa e alguns de seus textos aqui mencionados foram escritos e publicados posteriormente à obra dos demais autores. Nosso objetivo com o presente trabalho, porém, não é o de constituir uma linha cronológica em torno do conceito de valoração, mas o de apresentá-lo a partir de uma leitura das obras do Circulo.
} 
enunciado à luz das reverberações da interação social; portanto, a valoração é operacionalizada, potencializada e atravessada no enunciado à luz destas reverberações da situação de interação social, isto é, o imbricamento entre os horizontes espacial-temporal, axiológico e temático, conforme Volochínov (2013). Desse modo, as questões que orbitam na interação social matizam e dão sentido à avaliação que se modela, se regulariza e se legitima no interior do enunciado.

A valoração é um elemento constitutivo-funcional do enunciado. Portanto, os elementos da língua que compõem a estrutura desse respondem à valoração. A funcionalidade do enunciado é, portanto, valorativa, avaliativa. Desse modo, a valoração é um elemento que é tanto constitutivo quanto funcional.

Ademais, a valoração é índice social, que é avaliativo, expressivo e axiológico do enunciado. Assim, todo enunciado reflete e refrata certo recorte do mundo social, uma certa projeção do mundo social, ou como Volochínov (2013) pontua em "O discurso na vida e o discurso na arte", o enunciado é como um cenário da vida social. Esse cenário é sempre um cenário social-avaliativo, social-expressivo e social-axiológico, porque traz, na sua natureza, na sua organicidade, um tom que é avaliativo dessa projeção que se enuncia.

A valoração determina as escolhas linguísticas e composicionais do enunciado, e a valoração determina os sentidos do enunciado. À luz dessas considerações, compreendemos que realizamos um breve um recorte de alguns dos ensaios de V. Volochínov, P. Medviédev e M. Bakhtin, mas acreditamos que se torna claro nesta presente discussão, o quanto os autores convergem com as discussões em torno do papel da valoração/ avaliação social na construção do enunciado. Ao darmos continuidade às reflexões, nos direcionamos às respostas dadas em pesquisas contemporâneas em ADD.

\section{O estudo da valoração nas discussões contemporâneas em Análise Dialógica do Discurso}

Seguindo, portanto, em resposta aos escritos do Círculo, trazemos, inicialmente, a proposta de discussão de Rodrigues e Acosta Pereira (2014). A princípio, os autores discutem a proposta de um posicionamento axiológico em face à ideologia. Isso significa, portanto, que os sistemas ideológicos dos campos de atividade humana e os posicionamentos assumidos por parte dos sujeitos, como seres sócio-históricos, refletem na forma como um enunciado será valorado. Esta premissa, de acordo com Acosta Pereira e Rodrigues (2014) surge como uma contraposição dos teóricos do Círculo em virtude do pensamento linguístico do final do século XIX e início do século $X X$, onde o psiquismo individual refletia a essência da linguagem produzida por um sujeito. Os autores, ainda, acrescentam que "nesse contexto, observa-se o postulado da não neutralidade dos discursos, uma vez que estes são sempre marcados pela valoração de uma dada ideologia" (ACOSTA PEREIRA; RODRIGUES, 2014, p. 178).

Nessa proposta, os autores propõem fazer um percurso investigativo nas obras do Círculo em relação ao conceito de valoração/avaliação social e apresentam um encaminhamento possivel de análise da valoração como materialidade da ideologia. De tal modo, parte-se do cronotopo, ou seja, o cronotopo como porta de entrada da análise da valoração. Nessa perspectiva, as amplitudes espaço-temporais que engendram sentidos no discurso respondem a questões de avaliação dessa própria amplitude. Com isso, os enunciados e os gêneros do discurso, enunciados que se tornam relativamente estabilizados nas relações de interação social, acabam que materializando, nas relações dialógicas, os confrontos verbo-axiológicos, ou confrontos entre valorações, que se instauram na vida do discurso, em resposta às reverberações do cronotopo. Assim sendo, os autores esclarecem:

Para Bakhtin, em cada época, em cada percurso da história, os enunciados são construídos a partir de determinados valores, que se entrecruzam e se enriquecem com outros sentidos, à medida que o curso da história absorve outras projeções. Em cada época, em cada campo de atividade e em cada círculo social. os enunciados são construidos e reconstruídos, à medida que valores são ressignificados. Essa ressignificação não apenas opera no curso da projeção sócio-histórico-cultural, mas, 
essencialmente, na interação continua com os enunciados do outro (ACOSTA PEREIRA; RODRIGUES, 2014, p. 191).

Os caminhos delineados por Acosta Pereira e Rodrigues (2014) se realizam por meio de quatro instâncias. Para os autores, a primeira instância seria a análise da construção axiológica projetada do homem e do mundo pelo cronotopo. Portanto, a primeira etapa de análise proposta por Acosta Pereira e Rodrigues (2014) é a de que haja, portanto, uma análise discursiva da construção de valor, da construção avaliativa de uma imagem de homem na vida social a partir do conceito de cronotopo e, portanto, desconstruindo as amplitudes espaço-temporais do discurso que resultam sobretudo em amplitudes que são de ordem valorativa.

Em uma segunda instância, os autores propõem a construção material e a marca valorativa das ideologias no discurso. Então os autores propõem que, neste segundo momento, haja uma análise desse discurso a partir da sua materialidade linguístico-textual que demarque os sentidos em torno dos modos de ver e apreender a realidade social, posto que as ideologias são de fato matizadas por um recorte valorativo. Ou seja, como que esses modos de ver e compreender a realidade social, que são as ideologias, são sempre modos que trazem recortes, modos que trazem referenciais de ordem valorativa.

Em uma terceira instância, a expressividade dos enunciados, marcando, portanto, questões de ordem de conteúdo, de estilo e de composição que vão respondendo as demandas da situação de interação atravessadas pela ordem axiológica da mesma situação.
E, ao fim, em uma quarta instância, as relações de sentido que as três instâncias precedentes provocam no enunciado, portanto as relações semântico-valorativas que se engendram nos enunciados são relações de ordem dialógica de modo que tratam das relações de sentido em que, no discurso, o sujeito diz para o mundo, diz sobre o mundo e diz com o mundo. E essas relações são sempre de ordem axiológica.

Então, na proposta de Acosta Pereira e Rodrigues (2014), temos quatro instâncias/sugestões, proposta, portanto, aberta, mas quatro instâncias que mobilizam a análise da valoração no discurso. Os autores propõem, portanto, analisar a valoração em uma interface com outros conceitos cunhados pelos teóricos do círculo de Bakhtin, tais como "ideologia", "enunciado", "cronotopo" e "dialogismo". Não há como, na visão dos autores, caracterizar a valoração sem que se entenda o diálogo que o conceito mantém com estes outros conceitos.

Por fim, o dialogismo, enquanto concepção de linguagem, parece mobilizar os demais conceitos e traz uma noção de língua atrelada aos entornos sociais que circundam os enunciados produzidos pelos falantes. Disto surge a noção de que os enunciados respondem, em certa medida, uns aos outros, não necessariamente em um movimento de concordância absoluta, mas, a partir de posições axiológicas oriundas da posição que ocupa o sujeito em seu cronotopo específico, há um revozeamento e uma ressignificação daquilo que já fora dito outrora em outros enunciados. Tendo em vista a exposição tecida pelos autores, elaboramos o Quadro 1 com questões norteadoras que busquem estabelecer o sentido entre as instâncias e a valoração: 
Quadro 1 - A valoração em interface com os conceitos de cronotopo, ideologia, enunciado e dialogismo

\begin{tabular}{|c|c|c|}
\hline $\begin{array}{l}\text { A instância } \\
\text { delineadora }\end{array}$ & Excertos da proposta dos autores & Questões norteadoras \\
\hline Cronotopo & $\begin{array}{l}\text { [...] o cronotopo nos apresenta não apenas uma } \\
\text { visão de homem social, mas uma visão axioló- } \\
\text { gica e ideologicamente constituída da realidade } \\
\text { de seu tempo. Essa visão de homem se constrói } \\
\text { seja em função do próprio quadro específico } \\
\text { de representação desse homem [...] (ACOSTA } \\
\text { PEREIRA; RODRIGUES, 2014, p. 187, grifo nosso). }\end{array}$ & $\begin{array}{l}\text { 1- Como se constitui a imagem de } \\
\text { homem tendo em vista as determina- } \\
\text { ções valorativas oriundas do tempo } \\
\text { e do espaço em que está inserido? } \\
\text { Como essa amplitude espaço-tem- } \\
\text { poral projeta visões de mundo? }\end{array}$ \\
\hline Ideologia & $\begin{array}{l}\text { [...] a seiva da existência da ideologia formaliza- } \\
\text { da e sistematizada é a ideologia do cotidiano, } \\
\text { uma vez que a avaliação crítica de toda produ- } \\
\text { ção ideológica se opera na/por essa ideologia } \\
\text { (ACOSTA PEREIRA; RODRIGUES, 2014, p. 179, } \\
\text { grifo nosso). }\end{array}$ & $\begin{array}{l}\text { 2- Como a ideologia do cotidiano e } \\
\text { os sistemas ideológicos organizados } \\
\text { revelam as atitudes valorativas em } \\
\text { uma situação de interação? } \\
\text { 3- Como as ideologias do cotidiano e } \\
\text { os sistemas ideológicos organizados } \\
\text { são moldados por atitudes valorati- } \\
\text { vas/posições avaliativas? }\end{array}$ \\
\hline Enunciado & $\begin{array}{l}\text { [...] a centelha da expressão não existe nem no } \\
\text { sistema da língua, nem na realidade objetiva } \\
\text { fora de nós: a emoção, o tom, os juízos de valor } \\
\text { somente surgem e se materializam no emprego } \\
\text { vivo da língua, em um enunciado concreto e } \\
\text { real (ACOSTA PEREIRA; RODRIGUES, 2014, p. } \\
\text { 184, grifo nosso). }\end{array}$ & $\begin{array}{l}\text { 4- De que forma os aspectos consti- } \\
\text { tuintes do enunciado, em ligação com } \\
\text { a situação concreta, (de)mostram os } \\
\text { posicionamentos axiológicos? }\end{array}$ \\
\hline Dialogismo & $\begin{array}{l}\text { [...] as relações dialógicas, como já dito, são rela- } \\
\text { ções de sentido que se realizam nos enunciados. } \\
\text { De acordo com o autor, dois enunciados, ao se } \\
\text { confrontarem em um dado plano de sentido, em } \\
\text { dada situação de interação, acabam sempre por } \\
\text { estabelecer relações dialógicas, que, para o au- } \\
\text { tor, são relações semântico-axiológicas (ACOSTA } \\
\text { PEREIRA; RODRIGUES, 2014, p. 190, grifo nosso). }\end{array}$ & $\begin{array}{l}\text { 5- Como o todo enunciativo é valo- } \\
\text { rado tendo em vista a situação de } \\
\text { interação? } \\
\text { 6- Como as relações semântico-axio- } \\
\text { lógicas, relações dialógicas, susci- } \\
\text { tam/provocam sentidos dos/aos } \\
\text { enunciados? }\end{array}$ \\
\hline
\end{tabular}

Fonte: Elaborado pelos autores, a partir de Acosta Pereira e Rodrigues (2014).

Nessa segunda parte, voltemo-nos às propostas de Acosta Pereira e Brait (2020a, 2020b). O primeiro estudo apresenta-se sobre o estatuto dialógico da palavra e o segundo, por sua vez, sobre a análise valorativa do discurso de notícias em revistas online direcionadas a mulheres. São dois estudos que tratam da questão teórico-metodológica e analítica em relação à valoração e ideologia no enunciado.

As propostas ratificam o pressuposto de que haja um movimento de intersecção entre ideologia e valoração, o que os autores denominam de "projeções ideológico-valorativas" (ACOSTA PEREIRA; BRAIT, 2020b), a fim de que se possa, no empreendimento da análise discursiva, um movimento orgânico, de intersecção entre a ideologia como visão de mundo, com formas de compreender, de apreender, de validar a realidade social e a valoração como esse índice de valor, de avaliação, de axiologias que vão relativamente regularizando e legitimando essa ideologia no discurso.?

Os autores partem de questionamentos como orientadores para a análise, em resposta à pro-

7 Ver Acosta Pereira e Brait (2020b). 
posta de Bakhtin (2011), no ensaio "Apontamentos de 1970-1971", de que todo sentido sempre responde a certas perguntas. Assim, na proposta de Acosta Pereira; Brait (2020b), os questionamentos são considerados como balizadoras da análise.

As questões estão, portanto, dispostas no Quadro 2.

Quadro 2 - Questões norteadoras da análise

\begin{tabular}{|c|c|}
\hline Instância & Questão norteadora \\
\hline Cronotopo & $\begin{array}{l}\text { Como determinado tempo- } \\
\text {-espaço trazem uma imagem } \\
\text { discursiva de sujeito ideoló- } \\
\text { gico-valorada? }\end{array}$ \\
\hline $\begin{array}{c}\text { Esfera } \\
\text { sociodiscursiva }\end{array}$ & $\begin{array}{l}\text { Como o locus social da } \\
\text { esfera legitima determinadas } \\
\text { projeções ideológico-valo- } \\
\text { rativas? }\end{array}$ \\
\hline $\begin{array}{l}\text { Situação de } \\
\text { interação }\end{array}$ & $\begin{array}{l}\text { Como uma situação de inte- } \\
\text { ração regulariza projeções } \\
\text { ideológico-valorativas? }\end{array}$ \\
\hline $\begin{array}{l}\text { Conteúdo } \\
\text { temático }\end{array}$ & $\begin{array}{l}\text { Como o objeto de discurso é } \\
\text { tematizado sob um determi- } \\
\text { nado tom ideológico-valo- } \\
\text { rativo? }\end{array}$ \\
\hline Estilo & $\begin{array}{l}\text { Como os recursos linguísti- } \\
\text { cos mobilizados respondem } \\
\text { a um determinado efeito de } \\
\text { sentido ideológico-valorati- } \\
\text { vamente marcado? }\end{array}$ \\
\hline Composição & $\begin{array}{l}\text { Como a orquestração e o } \\
\text { acabamento enunciativo res- } \\
\text { pondem a um determinado } \\
\text { efeito de sentido? }\end{array}$ \\
\hline
\end{tabular}

Fonte: Acosta Pereira e Brait (2020, p. 96-97, grifo dos autores).
Haja vistas as questões propostas, podemos nos perguntar, por exemplo, como determinado tempo e espaço trazem uma imagem discursiva de sujeito ideológico-valorado? Pensemos na atualidade sócio-histórica: como a polaridade politica traz imagens de sujeitos marcadas pela posição ideológica e como essas posições reverberam na constituição e no funcionamento do discurso nesse tempo e espaço específico? Na esfera: como o locus social da esfera legitima determinadas projeções ideológico-valorativas? Pensemos, por exemplo, na esfera jornalística, como esta legitima valores a reportar os fatos, como esses valores respondem às aspirações institucionais de cada empresa jornalística? $\mathrm{Na}$ situação de interação: como a situação de interação regulariza projeções que são ideológicas e axiológicas? Pensemos em como uma situação de interação pode legitimar valores quanto ao que se diz, como se diz, quem pode ou não participar desse dizer, e ainda legitima posições e papéis sociais dos interlocutores. Ainda, isso se engendra na questão do conteúdo temático; pensemos como, por exemplo, em gêneros do discurso variados, o recorte do conteúdo temático recebe/responde determinados valores. No estilo, pensemos por exemplo como uma modalização e uma referenciação trazem em si organicamente valores que são agenciados pelas escolhas lexicais, gramaticais e textuais (ACOSTA PEREIRA; BRAIT, 2020b).

Ademais, neste terceiro momento, retomamos a proposta de Acosta Pereira; Rohling (2020). Nesse trabalho, os autores propõem questões de análise da relação ideológico-valorativa no discurso. Assim como na proposta de Acosta Pereira e Brait (2020b), nessa discussão, os autores propõem questionamentos, tais como disposto no quadro a seguir: 
Quadro 3 - Questões norteadoras das noções ideológico-valorativas

\begin{tabular}{|c|c|c|}
\hline \multicolumn{2}{|c|}{$\begin{array}{l}\text { As dimensões constitutivas do gênero e as } \\
\text { instâncias norteadoras dos questionamentos }\end{array}$} & Questões norteadoras \\
\hline \multirow{5}{*}{ Dimensão social } & Cronotopo & $\begin{array}{l}\text { 1- Como a relação tempo-espaço é marcada ideológi- } \\
\text { co e valorativamente no discurso? }\end{array}$ \\
\hline & Interação discursiva & $\begin{array}{l}\text { 2- Como aspectos ideológicos e seus recortes valora- } \\
\text { tivos sinalizam para sentidos singulares nas situações } \\
\text { de interação discursiva textualizadas no discurso? }\end{array}$ \\
\hline & $\begin{array}{l}\text { Os sujeitos do dis- } \\
\text { curso }\end{array}$ & $\begin{array}{l}\text { 3- Como que as relações interpessoais e as posições } \\
\text { sociais assumidas pelos sujeitos marcam atravessa- } \\
\text { mentos que são sempre ideológicos e avaliativos? }\end{array}$ \\
\hline & Avaliação social & $\begin{array}{l}\text { 4- Quais as marcações ideológico-valorativas de lutas } \\
\text { de classes textualizadas no discurso? }\end{array}$ \\
\hline & Conteúdo temático & $\begin{array}{l}\text { 5- Quais as projeções de ideologias e os seus recor- } \\
\text { tes valorativos que balizam o conteúdo temático do } \\
\text { discurso? }\end{array}$ \\
\hline \multirow{3}{*}{$\begin{array}{l}\text { Dimensão verbo- } \\
\text {-visual }\end{array}$} & $\begin{array}{l}\text { Estilo linguístico e } \\
\text { semiótico }\end{array}$ & $\begin{array}{l}\text { 6- Como essa ideologia e seu tom valorativo/ava- } \\
\text { liativo mobilizam certos recursos estilísticos lexicais, } \\
\text { gramaticais e textuais na voz do autor? } \\
\text { 7- Como essa ideologia e seu tom valorativo mobili- } \\
\text { zam certos recursos visuais no todo enunciativo? }\end{array}$ \\
\hline & $\begin{array}{l}\text { Composição/constru- } \\
\text { ção composicional }\end{array}$ & $\begin{array}{l}\text { 8- Como a orquestração e o (relativo) acabamento } \\
\text { composicional das imagens e outros recursos semi- } \\
\text { óticos demarcam posições ideológicas e nuances } \\
\text { valorativas/avaliativas? }\end{array}$ \\
\hline & $\begin{array}{l}\text { Os temas suscitados } \\
\text { no(s) enunciado(s) }\end{array}$ & $\begin{array}{l}\text { 9- Como conteúdo temático, estilo e a composiciona- } \\
\text { lidade do curta agenciam forças ideológico-valorativas } \\
\text { nos enunciados? } \\
\text { 10- Como o enunciado (reflexiva e refrativamente) uma } \\
\text { realidade social dentre várias? }\end{array}$ \\
\hline
\end{tabular}

Fonte: Elaborado pelos autores, a partir de Acosta Pereira e Rohling (2020).

Os autores, neste trabalho, tratam especificamente de uma elaboração didática para o trabalho com o gênero "curta-metragem". Deste modo, a proposta que medeia os questionamentos dispostos no quadro vão ao encontro de uma mescla entre a teoria do Círculo acerca da ideologia e valoração, em interface com outros conceitos elencados, e uma proposta que, possivelmente, possa chegar ao ensino da língua. Com isso, os autores propõem uma noção aproximativa entre a teoria dos autores russos em consonância com o contexto de ensino de Língua Portuguesa na escola de Educação Básica.

Em um quarto momento, retomamos a proposta de Acosta Pereira, Rodrigues e Costa-Hübes (2019) que, por sua vez, discute uma relação te- órico-conceitual que procura balizar uma análise ideológico-valorativa do discurso, um caminho comparativo entre ideologia e valoração. Nessa proposta, entende-se ideologia como conjunto de reflexões e interpretações da realidade social. Valoração como elemento que integra a materialidade da palavra e seu sentido. Ideologia como um sistema de concepções orientado por interesses de um grupo ou classe social baseado em valores. E a valoração como uma atualidade histórica que integra o enunciado e sua potencialidade de sentido. A proposta apresenta treze considerações teórico-conceituais sobre cronotopo, ideologia e valoração como um caminho possivel de um construto, de uma arquitetônica metodológica 
para a análise do discurso tendo como foco as questões de ideologia e de valoração.

A partir das considerações dos autores, buscamos sintetizar as ideias apresentadas por eles no Quadro 4, visando mobilizar as considerações tecidas acerca do cronotopo, da ideologia e dos indices de valoração:

Quadro 4 - O cronotopo, a ideologia e a valoração como elementos centrais nas questões intrínsecas à linguagem e aos estudos do discurso na visão do Círculo

\begin{tabular}{|c|c|c|}
\hline Cronotopo & Ideologia & Valoração \\
\hline $\begin{array}{l}\text { 1. Unidade fundamental na } \\
\text { percepção humana da realidade } \\
\text { cotidiana; } \\
\text { 2. Combinação coerente de } \\
\text { indicadores sócio-históricos da } \\
\text { relação entre tempo e espaço; } \\
\text { 3. Categoria por meio da qual os } \\
\text { sujeitos percebem e compreen- } \\
\text { dem o mundo social; } \\
\text { 4. Evidência histórica de ativi- } \\
\text { dades sociais manifestada em } \\
\text { textos; } \\
\text { 5. Amplitude ideológico-valora- } \\
\text { tiva da amplitude espaço-tem- } \\
\text { poral dos textos; } \\
\text { 6. "I...] meios de armazenar e } \\
\text { transmitir formas de experiên- } \\
\text { cia e conhecimento humanos" } \\
\text { (BEMONG; BORGHART, 2015 } \\
\text { apud ACOSTA PEREIRA; CoS- } \\
\text { TA-HÜBES; RODRIGUES, } 2019 \text {, } \\
\text { p. 252). } \\
\text { 7. Forma significativa de uma } \\
\text { determinada imagem de sujeito; } \\
\text { 8. Visão de mundo social no } \\
\text { texto; } \\
\text { 9. Correlação orgânica com prá- } \\
\text { ticas culturais especificas; } \\
\text { 10. Impulso gerativo de discur- } \\
\text { sos e suas formas tipicas; } \\
\text { 11. Construção semântica de or- } \\
\text { dem representacional e refratária; } \\
\text { 12. Base para a "memória de/ } \\
\text { dos gêneros do discurso"; } \\
\text { 13. Principio de construção de } \\
\text { mundos discursivos. }\end{array}$ & $\begin{array}{l}\text { 1. Conjunto de reflexões e inter- } \\
\text { pretações da realidade social; } \\
\text { 2. Sistema de concepções, orien- } \\
\text { tado por interesses de um grupo } \\
\text { ou uma classe social; } \\
\text { 3. Valores que condicionam com- } \\
\text { portamentos e atitudes e orienta } \\
\text { a práxis; } \\
\text { 4. "I...] parte de uma realidade } \\
\text { natural e social [...] (VOLOCHINOV, } \\
\text { 1929 apud ACOSTA PEREIRA; RO- } \\
\text { DRIGUES; COSTA-HÜBES, 2019). } \\
\text { 5. Construção dialética estabeleci- } \\
\text { da na relação com o mundo, com } \\
\text { a vida; } \\
\text { 6. Compreensão da organização } \\
\text { da estrutura social e das suas } \\
\text { regulações cronototipicas; } \\
\text { 7. Sustentação das relações so- } \\
\text { ciais que são externas ao sujeito, } \\
\text { refletidas e refratadas por meio de } \\
\text { signos; } \\
\text { 8. Constituição signnica das pala- } \\
\text { vras compreendidas como signo } \\
\text { social e ideológico; } \\
\text { 9. Reflexão e refração da realidade } \\
\text { que lhe é exterior; } \\
\text { 10. Ciência das ideias; } \\
\text { 11. Expressão das tomadas de } \\
\text { decisões e da práxis; } \\
\text { 12. Intersecção de interesses } \\
\text { sociais orientados de diferentes } \\
\text { formas em uma mesma comuni- } \\
\text { dade signica; } \\
\text { 13. Materializa-se na linguagem; } \\
\text { por isso a linguagem nunca é neu- } \\
\text { tra. Ela reflete e refrata sempre } \\
\text { uma ideologia. }\end{array}$ & $\begin{array}{l}\text { 1. Elemento que integra a materiali- } \\
\text { dade da palavra e o seu sentido; } \\
\text { 2. Atualidade histórica que integra o } \\
\text { enunciado e sua potencialidade de } \\
\text { sentido; } \\
\text { 3. Individualização, concretude } \\
\text { e situacionalidade do sentido do } \\
\text { enunciado; } \\
\text { 4. Matriz de seleção/escolha dos } \\
\text { recursos linguisticos nos limites do } \\
\text { enunciado; } \\
\text { 5. Matriz de seleção/escolha do } \\
\text { conteúdo e da forma composicional } \\
\text { do enunciado; } \\
\text { 6. Atmosfera axiológica do enunciado; } \\
\text { 7. Orientação avaliativa no meio ideo- } \\
\text { lógico de qualquer enunciado; } \\
\text { 8. Matriz que regulariza a fisionomia } \\
\text { sócio-histórica e seus efeitos na } \\
\text { interação; } \\
\text { 9. Caráter expressivo do enunciado; } \\
\text { 10. Expressão mais pura e típica da } \\
\text { entoação; } \\
\text { 11. Gesto valorativo do enunciador } \\
\text { em relação ao enunciado de outrem; } \\
\text { 12. Horizonte de valores que consubs- } \\
\text { tanciam os sentidos da interlocução; } \\
\text { 13. "[...] mediação entre a língua, } \\
\text { como um sistema abstrato de possi- } \\
\text { bilidades, e sua realidade concreta. A } \\
\text { avaliação social [valoração] deter- } \\
\text { mina o fenômeno histórico vivo, o } \\
\text { enunciado, tanto do ponto de vista } \\
\text { das formas linguisticas selecionadas } \\
\text { quanto do ponto de vista do sentido } \\
\text { escolhido" (MEDVIÉDEV, 2012[1928] } \\
\text { apud AcosTA PEREIRA; RODRIGUES; } \\
\text { cosTA-HüBES, 201g). }\end{array}$ \\
\hline
\end{tabular}

Fonte: Elaborado pelos autores, a partir de Acosta Pereira, Rodrigues e Costa-Hübes (2019).

Nessas propostas, observamos um postulado da não neutralidade dos discursos, uma vez que esses são marcados pela valoração de uma dada ideologia. Inicialmente, ainda, importa salientar nessa nossa discussão que, pela ancoragem filosófico-linguística do Círculo, a concepção de valoração não encontra eco nos estudos idealistas do final do século XIX e do início do século XX. Isso 
fica claro tanto na questão estética, ética e psiquica. Retomemos, por exemplo, a questão ética nas discussões de Bakhtin (2017) em Para uma filosofia do ato responsável e a relação desse sujeito em evento, sujeito-evento atravessado por um tom emotivo-volitivo do mundo. ${ }^{8}$ Da questão estética, como Volochínov (2013) discute em O discurso na vida e o discurso na arte, o enunciado estético em contraponto a estética objetivista e psicologista, propondo uma poética sociológica; e no campo psíquico, a discussão de Volochínov (2013) em O freudismo, em que Volochínov faz um estudo comparativo entre o que seria a psicologia objetivista e a psicologia subjetivista ou experimental para propor uma psicologia de ordem sociológica.

A discussão de valoração tanto no campo ético, estético e psíquico, no conjunto da obra do Círculo, sempre vêm como um movimento que refuta as posições, sejam elas objetivistas, sejam subjetivistas, do final do século XIX e início do século XX. Isso fica claro no ensaio Sobre as fronteiras entre a poética e a linguistica de Volochínov (2013). Volochínov nos coloca a seguinte questão:

A fim de evitar mal entendidos, parece-nos necessário destacar que aquilo que entendemos por 'valor' não tem nada a ver com a concepção idealista que era corrente na Psicologia e na Filosofia no final do século XIX e início do século $X X$. Nós operamos com o conceito de valor ideológico, que não objetiva a nenhuma 'universalidade', mas que carrega uma significação social e, mais precisamente, uma significação de classe $^{9}$ (VOLOSHINOV, 1981, p. 254).

Deste modo, o olhar para estes trabalhos em face aos escritos de Bakhtin e o Círculo nos apresenta uma cosmovisão teórico-metodológica de como o conceito de valoração é permeado e transpassado por outros conceitos advindos da linguagem dos autores russos. Assim sendo, temos que o cronotopo (BAKHTIN, 2016), enquanto instância espacial e temporal, não apenas reflete e refrata as posições valorativas presentes nos enunciados, mas também ressignifica os modos como o enunciado se constitui; os campos de atividade humana e/ou esfera da comunicação humana (VOLÓCHINOV, 2017) regulamenta a interação discursiva permeada por índices valorativo-axiológicos; a forma e a composição (BAKHTIN, 2016) dos enunciados são diretamente afetados não apenas pela posição enunciativo-axiológica que ocupam os interlocutores em um dado campo de atividade humana, mas também pelas escolhas de gêneros do discurso que são ressignificados em interações definidas; do mesmo modo, as escolhas de recursos linguísticos e semióticos (BAKHTIN, 2015) na constituição do todo enunciativo são advindas das valorações dos sujeitos; por fim, estas noções acabam por influenciar na forma e no tratamento das posições assumidas frente ao tema/conteúdo temático (BAKHTIN, 2016; VOLÓCHINOV, 2017) do enunciado.

Dito isto, passamos agora a refletir como as ideias trazidas pelos teóricos do círculo se consolidam quanto aos índices de valoração explorados nesta seção. Deste modo, discutimos a questão da valoração, tendo em vista seu horizonte espacial e temporal, a ideologia que a constitui e sua relação concreta com os aspectos linguísticos e composicionais que compõem o todo enunciativo.

\section{Outras reflexões}

De acordo com Acosta Pereira e Rodrigues (2014),
[...] podemos observar que a noção de valoração é de base ideológica, o que nos leva à necessi- dade de compreensão do conceito de ideologia e sua relação com a linguagem. Embora esse conceito seja fundante e perpasse toda a obra do Círculo, tal qual acontece com [os] outros conceitos, tratados na sua inter-relação [...], com vista a construí-los no movimento das práticas discursivas e da sua formulação teórica, poucas vezes vamos encontrar uma definição acabada e isolada de ideologia (RODRIGUES; ACOSTA PEREIRA, 2014, p. 178).

A ideologia, no ideário de Bakhtin e o Círculo, se entretece com uma grande variedade de outros

\footnotetext{
8 Embora tomemos neste momento o conceito de "ética" e "estética" por razões teóricas, nosso objetivo não é o de aprofundar tal discussão neste trabalho.

9 Essa significação social, respondente a uma significação de classe, é extensivamente discutida por Volochinov no ensaio de $1930 \mathrm{~A}$ palavra e suas funções sociais.
} 
conceitos mobilizados no todo arquitetônico da obra dos autores. A primeira correlação, que pode ser estabelecida, é com o conceito de campo de atividade humana, explorado principalmente por Volóchinov (2017), em Marxismo e Filosofia da Linguagem, e por Bakhtin (2016), na obra Os gêneros do discurso. Os autores estabelecem esta relação ao afirmar que tais campos são ideologicamente organizados, de modo que a ideologia do cotidiano esteja relacionada às práticas sociais de uso da linguagem em contextos do dia a dia e no diálogo face a face. A ideologia dos campos especializados, por sua volta, se revela a partir dos campos ideologicamente organizados. De outro modo, nas esferas de atividade humana que requerem práticas sociais de uso da linguagem mais profundas e sistematizadas.

Ainda, podemos recorrer à ideologia relacionando-a com o cronotopo, isto é, nas relações de tempo e espaço que circundam as práticas de interação discursiva. Conforme estabelecido na última seção, o cronotopo surge como um elemento que determina o modo das interações tendo em vista a sua natureza social, que é capaz de afetar, especialmente, a escolha de gêneros do discurso e, por seguinte, os recursos de natureza linguística, tais como o estilo e a composição, para o estabelecimento de um conteúdo temático no todo enunciativo.

Deste modo, já que a natureza linguística é afetada por relações de espaço e tempo, os autores concebem que tais escolhas são valorativo-axiológicas e, portanto, não apenas o campo de atividade humana e o momento histórico e espacial determinam o tom do enunciado. A valoração dos sujeitos frente ao tema, determinados por sua inserção ideológica em um dado contexto é capaz de afetar diretamente os enunciados e, deste modo, a interação como um todo, pois é por meio dela que as ressignificações e o horizonte axiológico se manifestam.

Medviédev (2012, p. 185) ainda nos diz que "é impossivel compreender um enunciado concreto sem conhecer sua atmosfera axiológica e sua orientação avaliativa no meio ideológico". O autor ainda nos pontua que "a palavra se torna um material do enunciado apenas como expres- são da avaliação social. Por isso, a palavra entra no enunciado não a partir do dicionário, mas a partir da vida" (MEDVIÉDEV, 2012, p. 185). E essa discussão da palavra na vida também é extensivamente discutida por Volochínov no ensaio A palavra e suas funções sociais (VOLOCHÍNOV, 2013). E, ainda, Medviédev pontua que:

[...] as possibilidades de uma lingua tornam-se realidade somente por meio da avaliação. Por que duas determinadas palavras ficam lado a lado? A Linguistica se restringe a explicar o porquê desse fato." INeste momento, sabemos que se trata de um dos estudos da sintaxe, por exemplo.] "Porém, dentro dos limites das possibilidades linguísticas, não se pode explicar o que porquê disso. Para tanto, será preciso chegar até a avaliação social e transformar uma das possibilidades gramaticais em um fato concreto da realidade discursiva" (MEDVIÉDEV, 2012, p. 187).

De todo modo, seja pela leitura de Volochínov, de Medviédev ou de Bakhtin, entendemos que a linguagem do Círculo acerca da valoração orbita em torno dos mesmos conceitos e fatores. A avaliação social, portanto, parte de um aspecto amplo de caráter sociológico para, em seguida, chegar aos aspectos linguístico-composicionais que dão forma ao enunciado vivo e concreto em ligação direta com essa natureza sociológica constitutiva.

Volochinov (2017) segue a seguinte explicação em relação à materialidade da língua e à valoração:

[...] as categorias linguísticas, tais como são, só são aplicáveis no interior do território da enunciação. Assim, as categorias morfológicas só têm sentido no interior da enunciação: elas deixam de ser úteis quando se trata de definir o todo. O mesmo se dá com as categorias sintáticas, por exemplo, a oração: a categoria oração é meramente uma definição da oração como uma unidade dentro de uma enunciação, mas nenhuma maneira como entidade global. [...]

Se ficamos nos limites das categorias gramaticais, jamais poremos a mão sobre a enunciação completa. As categorias da língua puxam-nos obstinadamente da enunciação e de sua estrutura para o sistema abstrato da lingua. [...]

Apenas o estudo das formas da comunicação verbal e das formas correspondentes da enunciação completa pode lançar uma luz sobre o sistema. Só se tornarão produtivos se forem combinados com uma compreensão adequada das bases da comunicação verbal (VOLOCHÍNOV, 2017, p. 146, 147, 148). 
Volochínov ainda, nas partes III, IV e V do ensaio "A palavra na vida e a palavra na poesia: introdução ao problema da poética sociológica" (VOLÓCHINOV, 2019), nos esclarece alguns conceitos, como valoração compartilhada, avaliação conjunta, resumo valorativo, comunidade de valorações, valorações subtendidas, revaloração, entonação, metáfora entonacional, valoração convincente e movimento valorativo

Tais conceitos são explicados por Volochínov neste ensaio e que correspondem às discussões que estamos empreendendo neste trabalho.

Também no ensaio de Volochínov A palavra e suas funções sociais (VOLOCHÍNOV, 2013), em relação à valoração, Volochínov mobiliza os seguintes conceitos: orientação social da enunciação, estilística do discurso, horizonte ideológico, resposta avaliativa, reação semântico-ideológica, luta de classes, relações de classe, ponto de vista e valor estilístico. Ressaltamos que também cabe uma boa leitura desse ensaio, atentando para esses conceitos que são mobilizados e explicados por Volochínov.

Bakhtin, em O freudismo, e aqui valemo-nos da tradução do Paulo Bezerra, que, ainda, apresenta a dupla assinatura. Portanto, Volochínov/Bakhtin, em O freudismo, esclarece que:

[...] o que caracteriza precisamente uma dada enunciação - [e portanto] a escolha de certas palavras, certa teoria da frase, [e] determinada entonação da enunciação - é a expressão da relação recíproca entre os falantes e todo o complexo ambiente social em que se desenvolve a conversa. [E] a questão não muda se em vez de discurso exterior temos discurso interior (BAKHTIN, 2017, p. 79-80).

Portanto, seja o discurso interior, seja o discurso exterior, ambos são qualitativamente são equivalentes em relação à valoração. Ou seja, ambos são atravessados pela valoração. Ainda em $O$ freudismo, Volochínov/Bakhtin pontua a questão da ideologia como expressão da consciência de classe, um clima social complexo e singular em que se constroem as enunciações, esse clima social complexo é sempre valorativo; a questão do discurso exterior e interior como ideológicos, e o meio social dando ao homem palavras e as unindo a determinados significados e apreciações. Portanto, temos a apreciação como um tom avaliativo.

Bakhtin, em Questões de estilistica no ensino de linguas, também nos coloca a seguinte explicação:

toda forma gramatical é, ao mesmo tempo, um meio de representação. Por isso, todas as formas podem e devem ser analisadas do ponto de vista das suas possibilidades de representação e de expressão, isto é, esclarecidas de uma perspectiva estilistica (BAKHTIN, 2013, p. 24-25).

Deste modo, novamente, temos a questão da expressão como tom avaliativo. Por fim, em sintese, temos: a valoração que se engendra no enunciado à luz da interação; a valoração como um elemento que é constitutivo e funcional do enunciado; a valoração como um índice social avaliativo; e a valoração determinando as escolhas linguísticas e composicionais e a valoração determinando o sentido do enunciado.

Além disso, "reflexo das relações entre os homens no discurso, sua hierarquia social. Inter-relação das unidades do discurso. Sensação aguda de mim mesmo e do outro na vida do discurso. Papel excepcional do tom" (BAKHTIN, 2011, p. 391). Vejamos a questão da avaliação pontuada no ensaio de Bakhtin "Apontamentos de 1970-1971".

Ainda, finalizamos com a seguinte passagem de O freudismo (BAKHTIN, 2017) que nos resume as discussões deste trabalho:

[...] efetivamente, não existe o individuo biológico abstrato. Aquele indivíduo biológico que se tornou o alfa e o ômega da ideologia atual. Não existe o homem fora da sociedade, consequentemente fora das condições socioeconômicas objetivas. Trata-se de uma abstração simplória. O individuo humano só se torna historicamente real e culturalmente produtivo como parte do todo social. Na classe e através da classe. Para entrar na história, é pouco nascer fisicamente. Assim nasce o animal, mas ele não entra na história. É necessário algo como um segundo nascimento, um nascimento social. Só essa localização social e histórica do homem o torna real e lhe determina o conteúdo da criação da vida e da cultura. Todas as tentativas de evitar esse segundo nascimento social e deduzir tudo das premissas biológicas da existência do organismo são irremediáveis e estão condenadas ao fracasso. Nenhum ato do homem integral, nenhuma formação ideológico-concreta pode ser explicada e entendida sem que se incorporem as condições socioeconômicas. Além do mais, nem as questões específicas da 
biologia encontrarão solução definitiva sem que se leve plenamente em conta o espaço social do organismo humano. Porque a essência humana não é o abstrato inerente ao indivíduo, é o conjunto das relações sociais em sua efetividade.

\section{Considerações finais}

Deste modo, a conclusibilidade, isto é, o acabamento deste trabalho propõe interseccionar as considerações trazidos pelos teóricos do Círculo em consonância com o proposto pelas pesquisas em ADD analisadas. Desse modo, retomando o escopo das considerações tecidas por Mikhail Bakhtin, Pavel Medviédev e Valentin Volochinov, temos a valoração como: um construto de sentidos determinados pelo contexto do enunciado; uma orientação do eu para o outro estabelecida pelo horizonte espacial e temporal, observável, principalmente, pelo cronotopo. Aqui acrescenta-se ainda o acabamento dos enunciados como tom apreciativo frente à interação; uma seleção dos recursos estilísticos, que se dá em virtude de um auditório social e pode evocar sentidos de estilos de linguagem individuais, dando o tom valorativo do enunciador frente à situação de interlocução em que se encontra.

Dito isso, passamos aos trabalhos contemporâneos inseridos no campo da Linguística Aplicada, que mobilizam a ADD como combustível que fomenta a tecitura metodológica proposta pelos autores. Em Acosta Pereira e Rodrigues (2014), a mobilização do conceito de cronotopo, ideologia, composição e estilo e relações dialógicas dá o tom do primeiro aspecto proposto pelos autores do círculo, isto é, de que o enunciado é circuncidado pelos entornos sociais que, impregnados de conteúdo ideológico-valorativo, passam a estabelecer os caminhos da interação discursiva, resultadas em enunciados concretos.

Nos trabalhos de Acosta Pereira e Brait (2020a, 2020b), os questionamentos buscam elencar as projeções valorativas frente à ideologia e aos aspectos constituintes do processo enunciativo. Deste modo, a construção dos questionamentos remete aos passos metodológicos cunhados pelos autores do circulo, uma vez que partem de um horizonte social mais amplo para, por fim, chegar à materialidade concreta do enunciado. Esta cosmovisão do enunciado nos permite entender o enunciado, como algo concreto no fluxo da interação discursiva. Por fim, a proposta vai ao encontro das ideias propostas por Bakhtin "Metodologia das ciências humanas" (BAKHTIN, 2011), contido da coletânea de ensaios publicado no livro Estética da criação verbal. Nesse ensaio, o autor assevera que a porta de entrada para qualquer estudo deve partir de um enunciado concreto, vivo e entendido de seu ponto de vista com a interação discursiva como um todo.

Do mesmo modo, Acosta Pereira e Rohling (2020) e Acosta Pereira, Rodrigues e Costa-Hübes (2019), visando apresentar uma proposta que considere o contexto de ensino como mote para as discussões entre linguagem, valoração e ideologia, apresentam questionamentos e considerações sobre conceitos, que consideram a valoração e a ideologia como uma gama de recursos para aclarar aspectos de leitura e compreensão. Deste modo, apenas o trabalho que considere os gêneros do discurso pode contribuir para que esta visão dialógica se estabeleça de forma concreta e para o entendimento da interação como um todo.

Por fim, destacamos a importância de estabelecer diálogos com os demais conceitos apresentados pelos autores do círculo. O cronotopo e a ideologia são determinantes para a compreensão dos movimentos valorativos dos interlocutores frente aos enunciados e à interação como um todo. Não seria possivel, pois, estabelecer a ideia da valoração sem captar estes demais aspectos.

\section{Referências}

ACOSTA PEREIRA, Rodrigo; RODRIGUES, Rosângela Hammes. O conceito de valoração nos estudos do Círculo de Bakhtin: a inter-relação entre ideologia e linguagem. Linguagem em (Dis)curso - LemD, Tubarão, SC, v. 14, n. 1, p. 177-194, jan./abr. 2014.

ACOSTA-PEREIRA, Rodrigo; RODRIGUES, Rosângela Hammes: COSTA-HÜBES, Terezinha da Conceição. O estudo dos gêneros do discurso sob a perspectiva dialógica da linguagem: considerações sobre cronotopo, ideologia e valoração. In: NASCIMENTO, Elvira Lopes do; CRISTÓVÃO, Vera Lúcia Lopes; LOUSADA, Eliane. (org.). Gêneros de texto/discurso: novas práticas e desafios. 1. ed. Campinas: Pontes, 2019. v. 1. p. 349-370. 
ACOSTA PEREIRA, Rodrigo; BRAIT, Beth. A valoração em webnotícias direcionada às mulheres. Revista da Anpoll, [S. I.], v. 51, p. 89-107, 2020a. Disponivel em: https://revistadaanpoll.emnuvens.com.br/revista/ article/view/1394. Acesso em 28 ago. 2021.

ACOSTA PEREIRA, Rodrigo; BRAIT, Beth. Revisitando o estudo/estatuto dialógico da palavra. Linguagem em (Dis)Curso, [S. I.], v. 1, p. 125-142, 2020b. Disponivel em: http://www.portaldeperiodicos.unisul.br/index.php/ Linguagem_Discurso/article/view/7727. Acesso em 28 ago. 2021

ACOSTA PEREIRA, Rodrigo; ROHLING, Nivea. Ideologia e valoração/avaliação social: revisitando conceitos na perspectiva dialógica. Caminhos em Linguistica Aplicada, [S. I.] V. 23, p. 15-35, 2020.

BAKHTIN, Mikhail. Apontamentos de 1970-1971. In: BAKHTIN, Mikhail. Estética da criação verbal. Tradução de Paulo Bezerra. 6. ed. São Paulo: Editora WMF Martins Fontes, 2011. p. 367-392.

BAKHTIN, Mikhail. Questões de estilistica no ensino da lingua. Tradução de Sheila Grillo e Ekaterina Vólkova Américo. São Paulo: Editora 34, 2013.

BAKHTIN, Mikhail. O discurso no romance. In: BAKHTIN, Mikhail. Questões de literatura e de estética: a teoria do romance. Tradução de Aurora Fornoni Bernardini. 7. ed. São Paulo: Hucitec, 2014. p. 71-210.

BAKHTIN, Mikhail. Teoria do romance l: a estilística. Tradução de Paulo Bezerra. 1. ed. São Paulo: Editora 34, 2015

BAKHTIN, Mikhail. Os gêneros do discurso. Tradução de Paulo Bezerra. São Paulo: Editora 34, 2016.

BAKHTIN, Mikhail. Para uma filosofia do Ato Responsável. Tradução de Valdemir Miotello, Carlos Alberto Faraco. São Carlos: Pedro \& João Editores, 2017.

BAKHTIN, Mikhail. O freudismo. Tradução de Paulo Bezerra. São Paulo: Perspectiva, 2017.

MEDVIÉDEV, Pável Nokoláievich. O método formal nos estudos literários: introdução crítica a uma poética sociológica. Tradução de Sheila Camargo Grillo, Ekaterina Vólkova Américo. São Paulo: Contexto, 2016.

VOLOCHÍNOV, Valentin. Palavra na vida e palavra na poesia: introdução ao problema da poética sociológica. In: VOLOCHÍNOV, Valentin N. A construção da Enunciação e outros ensaios. São Carlos-SP: Pedro \& João, 2013. p. 71-100.

VOLOCHÍNOV, Valentin. A construção da enunciação. In: VOLOCHÍNOV, Valentin. A construção da Enunciação e outros ensaios. São Carlos-SP: Pedro \& João, 2013. p. 157-188.

VOLOCHINNOV, Valentin. Sobre as fronteiras entre a poética e a linguística. In: VOLOCHÍNOV, Valentin. A construção da Enunciação e outros ensaios. São Carlos-SP: Pedro \& João, 2013. p. 213-250

VOLÓCHINOV, Valentin. Marxismo e filosofia da linguagem: problemas fundamentais do método sociológico na ciência da linguagem. Tradução de Sheila Grillo e Ekaterina Vólkova Américo. São Paulo: Editora 34, 2017.
VOLÓCHINOV, Valentin. A palavra na vida e a palavra na poesia: para uma poética sociológica. In: VOLÓCHINOV, Valentin. A palavra na vida e a palavra na poesia: ensaios, artigos, resenhas e poemas. Tradução de Sheila Grillo e Ekaterina Vólkova Américo. 1. ed. São Paulo: Editora 34, 2019. p. 109-146.

\section{Agradecimentos}

Agradecemos à Fernanda Gregol Veronez pela tradução zelosa de nosso resumo para a língua espanhola.

\section{Rodrigo Acosta Pereira}

Doutor em Linguística pela Universidade Federal de Santa Catarina (UFSC), em Florianópolis, SC, Brasil; mestre em Linguistica pela Universidade Federal de Santa Catarina (UFSC), em Florianópolis, SC, Brasil; professor da Universidade Federal de Santa Catarina (UFSC), em Florianópolis, SC, Brasil.

\section{Fernando Arthur Gregol}

Mestre em Letras pela Universidade Estadual do Oeste do Paraná (UNIOESTE), em Cascavel, PR, Brasil; professor do Centro de Ensino de Línguas de Toledo (CELTO), em Toledo, PR, Brasil.

\section{Endereço para correspondência}

Rodrigo Acosta Pereira

Universidade Federal de Santa Catarina

R. Eng. Agronômico Andrei Cristian Ferreira, s/n

Sala 201-B, Bloco B - CCE

88040-900

Florianópolis, SC, Brasil

Fernando Arthur Gregol

Centro de Ensino de Línguas de Toledo - CELTO

Bloco de Ciências Sociais Aplicadas (CCSA)

Rua da Faculdade, 645

Jardim La Salle, 85903-000

Toledo, PR, Brasil

Os textos deste artigo foram revisados pela Poá Comunicação e submetidos para validação do(s) autor(es) antes da publicação. 